\title{
Novel Preparation of Functional $\beta$-SiC Fiber based In 203 Nanocomposite and Controlling of Influence Factors for the Chemical Gas Sensing
}

\section{Zambaga Otgonbayar}

Hanseo University

Young Jun Joo

Korea Institutes of Ceramic Engineering and Technology

Kwang Youn Cho

Korea Institutes of Ceramic Engineering and Technology

Sang Yul Park

Daeho I\&T

Kwang Youl Park

Daeho I\&T

Won-Chun Oh ( $\nabla$ wc_oh@hanseo.ac.kr)

Hanseo University

\section{Research Article}

Keywords: SiC fiber, hydrothermal, binary nanocomposite, gas sensing

Posted Date: November 8th, 2021

DOI: https://doi.org/10.21203/rs.3.rs-1031068/v1

License: (1) This work is licensed under a Creative Commons Attribution 4.0 International License.

Read Full License 


\section{Abstract}

The gas sensing ability of a pure SiC fiber is limited due to its low-sensitivity and selectivity with poor recovery time during a gas sensing test. The combination of functional $\beta$-SiC fibers with metal- oxide (MO) can lead to excellent electronic conductivity, boosted chemical activity, and high reaction activity with the target gas and $\mathrm{SiC}-\mathrm{In}_{2} \mathrm{O}_{3}$ sensor material. Influence factors such as amounts of $\mathrm{MO}$, current collectors, and gas species ( $\mathrm{CO}_{2}, \mathrm{O}_{2}$ and without gas) for the gas sensing ability of $\mathrm{SiC}-\ln _{2} \mathrm{O}_{3}$ nanocomposite were determined at standard room temperature $\left(25^{\circ} \mathrm{C}\right)$ and high temperature $\left(350^{\circ} \mathrm{C}\right)$ conditions. The gas sensing ability of the functional $\beta-\mathrm{SiC}$ fiber was significantly enhanced by the loading of $\operatorname{In}_{2} \mathrm{O}_{3}$ metal-oxide. In addition, the $\mathrm{MO}$ junction on the $\beta-\mathrm{SiC}$ fiber was mainly subjected to the Si-C-O-In bond sensor layer with an effective electron-transfer ability. The gas sensing mechanism was based on the transfer of charges, in which the sensing material acted as an absorber or a donor of charges. The sensor material could use different current- collectors to support the electron transfer and gas sensing ability of the material. A 1:0.5M SiC- $\mathrm{In}_{2} \mathrm{O}_{3}$ coated Ni-foil current collector sensor showed better sensing ability for $\mathrm{CO}_{2}$ and $\mathrm{O}_{2}$ gases than other gas sensors at room temperature and high temperature conditions. The sensing result of the electrode was obtained with different current density values without or with gas purging conditions because $\mathrm{CO}_{2}$ and $\mathrm{O}_{2}$ gases had electron acceptor properties. During the gas sensing test, the sensor material donated electrons to target gases. The current value on the $\mathrm{CV}$ graph then significantly changed. Our obtained sample analysis data and the gas sensing test adequately demonstrated that $\mathrm{MO}$ junctions on functional $\beta$-SiC fibers could improve the sensitivity of a sensor material and particularly upgrade the sensor material for gas sensing.

\section{Introduction}

Gas detection tests are used in important tests for engine capacity and chemical plants, especially hazardous gases. [1-5]. Sensing and detecting gases or molecules on a wide bandgap nanomaterial mainly depends on the physical and chemical properties of the material A wide bandgap semiconductor material is more useable and stable under high voltage and temperature. Silicon carbide $(\beta-\mathrm{SiC})$ has excellent thermal stability and strong electrical conductivity under high temperature conditions $\left(25^{\circ} \mathrm{C} \sim\right.$ $900^{\circ} \mathrm{C}$ ) [6-10]. Conventional pure silicon and carbon materials cannot resist extreme conditions. Thus, they are unacceptable for hazardous gas sensing performance. The strong resistance of electrochemical performance and stability properties of $\beta-S i C$ have changed the usability levels of silicon and carbon materials. However, $\beta$-SiC-based sensor materials also have disadvantages such as low-sensitivity and selectivity with poor recovery time during sensing [11-14]. Such disadvantages of the $\beta$-SiC-based sensor materials mentioned above are mainly due to the thickness of the sensor which has a thin-film and a miniature contact area. Recently, 2D-structured materials have been widely used for gas sensing experiments due to their large surface area to volume ratios, large absorbing capacities for gas molecules, and strong surface activities. Two-dimensional SiC materials have good gas sensing properties at high temperatures (above $300^{\circ} \mathrm{C}$ ) [15]. However, the sensing activity of pure $\mathrm{SiC}$ is not ideal due to the low reaction activity between the gas and the surface of the electrode. The most commonly 
used method to increase SiC activity is to combine $\beta$-SiC and MO (metal oxide) to form a gas-sensing material. This method can bring excellent electronic conductivity and boost chemical activity (enhanced chemical activity, interactivity of the gas and electrode surface).

Metal oxide (MO)-based sensor materials have a chemiresistive sensor feature because they are cheap and easy to operate, and are especially strongly related to instrument analysis [16, 17]. In our research, we combined $\beta-\mathrm{SiC}$ fibers with $\ln _{2} \mathrm{O}_{3}$, which has a wide bandgap energy (3.6-4.0 eV), good optical and electrical properties, and strong stability and usability features in gas sensing applications. The sensitivity of $\mathrm{MO}$ and $\beta-\mathrm{SiC}$ is mainly affected by the morphological structure and shapes of nanomaterials $[18,19]$. The gas sensing mechanism is based on the transfer of charges, with the sensing material acting as absorbers or donors of charges. The charge transfer between the gas molecule and the sensing material will cause changes in sensing material properties. The gas sensor works by bridging two electrodes (source and drain) with sensing materials and passing current through them. Gas detection can be realized by monitoring current changes upon exposure to the target gas environment under a constant voltage. For a conductance type gas sensor, both high sensitivity and a fast recovery rate are desirable [20]. The gas sensing performance of the electrode is influenced by the gas flow rate, humidity, temperature, and sensing material type and dimension factors. There are several approaches to improve the performance of a sensor such as using programming temperature, using UV light in the sensor, and using nanoparticles as catalysts to improve absorption and selectivity [21].

In this study, we synthesized $\ln _{2} \mathrm{O}_{3}$ nanoparticles via a low temperature, hydrothermal method using indium nitrate. The $\beta-S i C-\ln _{2} \mathrm{O}_{3}$ binary nanocomposite was synthesized following the same procedure. As-prepared nanocomposites were calcined at $400^{\circ} \mathrm{C}$ to obtain perfect morphological structures. The development of a gas sensing material with very sensitive and very selective sensing is important to construct a wearable gas sensing device. The characteristics of the nanocomposite were evaluated to define its surface state, ratio, and pore distribution. The as-prepared nanomaterials were then subjected to gas sensing tests. Gas selectivity was determined using different target gaseous products.

\section{Experiment Part}

\subsection{Preparation of $\ln _{2} \mathrm{O}_{3}$}

Pure $\ln _{2} \mathrm{O}_{3}$ was prepared by hydrothermal method. First, $50 \mathrm{ml} 0.3 \mathrm{M} \mathrm{Na}_{2} \mathrm{CO}_{3}$ and $\ln \left(\mathrm{NO}_{3}\right)_{3}$ solutions were prepared separately. These two solutions were then mixed and stirred $(400 \mathrm{rpm})$ for $3 \mathrm{~h}$ at $50^{\circ} \mathrm{C}$. To improve the supersaturation of $\mathrm{In}^{3+}$ ions in the solution, ultrasonication was conducted for $1 \mathrm{~h}$ at frequency of $50 \mathrm{kHz}$. The solution was transferred into a $100 \mathrm{ml}$ Teflon lined autoclave and kept at $190^{\circ} \mathrm{C}$ for $12 \mathrm{~h}$. Precipitated powder was collected by centrifugation at 8,000 rpm for $40 \mathrm{~min}$. The collected powder was washed with DI-water and ethanol to remove impurities and dried at $80^{\circ} \mathrm{C}$ in an electric oven. The powder was ground with an agate mortar and calcined in a sealed crucible at $400^{\circ} \mathrm{C}$ for $2 \mathrm{~h}$ with a heating speed of $10^{\circ} \mathrm{C} / \mathrm{min}$. 


\subsection{Preparation of $\mathrm{SiC}-\mathrm{In}_{2} \mathrm{O}_{3}$}

Binary nanocomposites were prepared using a hydrothermal method following an ultrasonication process. In detail, $1 \mathrm{M} \beta-\mathrm{SiC}$ fiber solution was prepared using a mixture of ethanol and DI-water $(25 \mathrm{ml}$ : $25 \mathrm{ml}$ ) and stirred for $1.5 \mathrm{~h}$ at room temperature. Meanwhile, an $\ln _{2} \mathrm{O}_{3}$ solution was prepared using the same solvent. The as-prepared solutions were mixed and stirred at $50^{\circ} \mathrm{C}$ for $3 \mathrm{~h}$ to prepare a homogeneous solution followed by ultrasonication for $1 \mathrm{~h}$ at a frequency of $50 \mathrm{kHz}$. The ultrasonication process resulted in rapid nucleation of $\mathrm{SiC}-\mathrm{In}_{2} \mathrm{O}_{3}$ and improved solute transfer. The solution was transferred to a Teflon lined autoclave and kept at $190^{\circ} \mathrm{C}$ for $12 \mathrm{~h}$. Precipitated powder was then collected by centrifugation at $8000 \mathrm{rpm}$ for $40 \mathrm{~min}$. The collected powder was washed with ethanol to remove impurities and dried at $80^{\circ} \mathrm{C}$ for $10 \mathrm{~h}$ in an electric oven. The powder was ground with an agate mortar and calcined in a sealed crucible at $400^{\circ} \mathrm{C}$ for $2 \mathrm{~h}$ with a heating speed of $10^{\circ} \mathrm{C} / \mathrm{min}$ to obtain wellstructured $\mathrm{SiC}-\ln _{2} \mathrm{O}_{3}$ binary nanocomposites. The molar ratio of $\ln _{2} \mathrm{O}_{3}$ in the binary nanocomposite varied from $0.5 \mathrm{M}$ to $0.1 \mathrm{M}(\mathrm{x}=0.5 \mathrm{M}, 0.3 \mathrm{M}, 0.1 \mathrm{M})$. It was possible to study how the percentage of $\ln _{2} \mathrm{O}_{3}$ could affect the electrochemical ability and morphological state of the final sample.

\subsection{Characterization}

\subsubsection{Sample characterization}

The crystal structure of the nanocomposite was analyzed by XRD (SHIMADZU XRD-6000) equipped with a Cu Ka X-ray source (1.5406 $\AA$ ). The resistivity of each binary nanocomposite was analyzed with EIS and a three-electrode system. The surface morphology and element percentages were analyzed with SEM (JSM-5600 JEOL, Akishima, Tokyo, Japan) incorporated with EDX. The vibrational mode of the sample was tested with a confocal-Raman imaging system using a $532.13 \mathrm{~nm}$ excitation laser (Renishaw in Via Reflex, NRS-5100). The size and shape of the nanomaterial were analyzed with TEM (Hitachi H9500, Tokyo, Japan). Elements in the material, surface structure, and electronic structure were tested with XPS (PHI 5000 Versa Probe).

\subsubsection{Gas sensing test}

The sensor response of the binary nanocomposite was tested using different gas purging systems. The sensor device was prepared with the following steps. First, as-prepared $\mathrm{SiC}-\mathrm{x} \ln _{2} \mathrm{O}_{3}$ was mixed with binding material (ethyl cellulose) and used to make a fine slurry with an ethanol dispersant. The asprepared slurry was spread on the current collector and the blade was used to adjust the thin-film on the collector surface. The coated electrode was dried at $30^{\circ} \mathrm{C}$ in an oven to make a uniform gel-layer on the current collector. The as-prepared electrode was placed in the gas-sensing reactor. The temperature in the reactor was room temperature $\left(25^{\circ} \mathrm{C}\right)$ and high temperature $\left(350 *{ }^{\circ} \mathrm{C}\right)$. The gas-flow rate was controlled with a mass-flow controller at $6 \mathrm{~kg} / \mathrm{cm}^{2}$ for $120 \mathrm{~min}$. During the gas flow condition without gas, the CV graph was measured by using a PGP201 potentiostat (A41A009). The current density in the CV graph 
was obtained from the ratio between the density amount before purging the gas and that after purging the gas.

\section{Results And Discussion}

\subsection{XRD pattern and EIS test}

The crystal structures and XRD patterns of the nanocomposites are shown in Figure 1a. The black diffraction peak indicated the XRD pattern of $\operatorname{In}_{2} \mathrm{O}_{3}$, which well-matched with the JCPDS No. 0.6-1416 card. The sharp peak and FWHM decrease indicated that the as-prepared $\ln _{2} \mathrm{O}_{3}$ nanocomposite had a decent crystal structure. The broad diffraction peak at 35.51 $2-\theta$ degrees indicated the (111) crystal plane of the $\beta$-SiC fiber (JCPDS No. 29-1129). In the XRD pattern of $S i C-\operatorname{In}_{2} O_{3}$, the peak of the $\ln _{2} \mathrm{O}_{3}$ was significantly changed to low-sharpness, indicating that $\mathrm{MO}$ could cover the surface of $\beta$-SiC-fibers with successful interactions between each nanocomposite. Figure $1 \mathrm{~b}$ shows the electrochemical resistance spectra of $\mathrm{SiC}-\ln _{2} \mathrm{O}_{3}$ binary nanocomposites containing different amounts of $\ln _{2} \mathrm{O}_{3}$.

The resistance and conductivity of the samples are mainly related to their semicircle profile in the EIS test. From the above results, it was found that the $0.1 \mathrm{M} \mathrm{In}_{2} \mathrm{O}_{3}$ loaded nanocomposite had a small semicircle with low resistance properties. It is effective for the electrochemical coefficient of the $\mathrm{SiC}-\mathrm{In}_{2} \mathrm{O}_{3}$ nanocomposite during the test. The SiC-fiber had good electrochemical conductivity. The effectiveness of the $\ln _{2} \mathrm{O}_{3}$ to $\beta$-SiC was lacking, and $\ln _{2} \mathrm{O}_{3}$ did not reduce or change the fundamental properties of the $\beta-$ $\mathrm{SiC}$ fiber. The EIS profiles of the samples were remarkably changed when the loading amount of $\ln _{2} \mathrm{O}_{3}$ was increased from $0.1 \mathrm{M}$ to $0.5 \mathrm{M}$, which might be due to the interconnection between the SiC fiber and MO.

\subsection{EDX and SEM analysis}

The surface state, morphology, and atomic amount of each element in the nanocomposite were analyzed by EDX and SEM. From the EDX results, the main elements were found in high amounts as shown in Figure 2. The N-element was found in the EDX result of $\ln _{2} \mathrm{O}_{3}$. This might be derived from the precursor material used for $\ln _{2} \mathrm{O}_{3}$ synthesis. After combining $\ln _{2} \mathrm{O}_{3}$ with $\beta$-SiC fiber followed by calcination, there was no amount of $\mathrm{N}$-element in the result. Other elements were not found either, confirming that the final sample was successfully synthesized without impurities using a simple hydrothermal method.

The surface morphology and profile of the as-prepared nanomaterials were analyzed by SEM. Pure $\beta-S i C$ fibers had a smooth and clear surface with all nanoparticles regularly agglomerated as shown in Figure 3 $(a, b)$. The thickness of the nanoparticles was the same, with a width of $11.3 \mathrm{~nm}$ and non-similar length. The smooth surface of the $\mathrm{SiC}$ fiber supports the location of $\ln _{2} \mathrm{O}_{3}$ on the surface, which can prevent MO from irregularly spreading on the surface. Pure $\mathrm{In}_{2} \mathrm{O}_{3}$ had irregularly shaped primary nanoparticles such as cubes and spheres, with all primary nanoparticles were agglomerated. The size of the cube-shaped nanoparticles was approximately $3.23 \mu \mathrm{m}$. The surface was smooth and thicker than sphere-shaped (in 
Figures 3c, d). The surface images of the different amount of metal oxide loaded $\mathrm{SiC}-\operatorname{In}_{2} \mathrm{O}_{3}$ nanocomposite were displayed in Figure $3(\mathrm{e}-\mathrm{j})$. The metal oxide agglomeration on the $\mathrm{SiC}$ fibers were non-similar due to the loading amounts. Especially, the agglomeration of the metal oxide was becoming strong in 1:0.5 M SiC-ln ${ }_{2} \mathrm{O}_{3}$ (in Figure $3 \mathrm{i}, \mathrm{j}$ ).

In SEM images of $\mathrm{SiC}-\mathrm{In}_{2} \mathrm{O}_{3}$, sphere-shaped $\ln _{2} \mathrm{O}_{3}$ was mainly observed on smoother $\beta$-SiC fibers. All nanoparticles were agglomerated, resulted in a porous structure profile with different sizes. Moreover, pure $\ln _{2} \mathrm{O}_{3}$ well-dispersed onto the surface, which can effectively increase the gas sensing performance.

\subsection{Molecular dimensional analyses by Raman spectra and TEM}

The symmetric motion, chemical bonding, and interaction of nanomaterials were analyzed by Raman spectroscopy. Vibrational frequencies are specific to the symmetric motion of molecules and chemical bonds in the final nanocomposite [22, 23]. Full Raman spectra are displayed in Figure 4. Raman peaks of pure $\mathrm{MO}$ were observed below $1200 \mathrm{~cm}^{-1}$ Raman shift regions. A total of six Raman peaks appeared in the $\ln _{2} \mathrm{O}_{3}$ nanocomposite. The first four peaks were related to $E_{1 g}, E_{2 g}$, and $A_{1 g}$-Raman active-modes. Indium hydroxide Raman peaks appeared in the $720.8 \mathrm{~cm}^{-1}$ and $1053.2 \mathrm{~cm}^{-1}$ frequency regions. These peaks might be due to the conversion of small amounts of In ions to $\ln (\mathrm{OH})_{3}$ during the synthesis process [24]. The pure $\beta$-SiC had two-sharp Raman peaks at $1332.2 \mathrm{~cm}^{-1}$ and $1596.6 \mathrm{~cm}^{-1}$ regions related to $\mathrm{sp}^{2}$-hybridized carbon and the optical branch of the second-order Raman spectra, respectively. One-broad peak was obtained at $2747.4 \mathrm{~cm}^{-1}$ Raman shift region. It was classified to $2 \mathrm{D}$ symmetric mode which can be obtained from the overtone motion of TO-phonons due to activation by double resonance scattering. After combining the SiC-fiber with MO, no MO-peak appeared in Raman result, although the peak intensity was increased. Such increases in the Raman intensity are related to a particular mode of vibration that appears in a specific bond to allow a specific Raman active mode. in otherwise, it is related to the expression of supressing and dominating bonds which are formed at the specific frequency energy.

The size and shape of the nanomaterial were analyzed by TEM. Obtained images are shown in Figure 5. In Figure $5(a, b)$,rod-shaped with short length and long-length $\beta$-SiC-fibers were obtained; the long-length SiC-fibers were dominant, which is more favourable for $\mathrm{MO}$ and allows uniform distribution on the surface. TEM images of $\ln _{2} \mathrm{O}_{3}$ revealed that particles were agglomerated and stacked and created the spherical and grain-shaped particles. The agglomerated particles had cleavage steps, indicating a nonsmoothed surface (Figures $5 \mathrm{c}, \mathrm{d}$ ). In $\mathrm{SiC}-\mathrm{In}_{2} \mathrm{O}_{3}$, the most MO wrapped the $\beta$-SiC-fiber surface and there was less agglomeration on the surface. $\mathrm{MO}$ nanoparticles were obtained as light black-grey coloured images. $\beta$-SiC-fibers were obtained as dark black colored rod-shaped images and the widths of the fibers were identical. The lower agglomeration of $\mathrm{MO}$ on $\beta-\mathrm{SiC}$ fibers can have favourable electrontransfer action during an electrochemical test. To summarize, the simple hydrothermal method could be used to synthesize well-spread $\ln _{2} \mathrm{O}_{3}$ on the surface of $\beta-\mathrm{SiC}$ fibers. This provides favourable conditions for efficient electronic conduction and good electrochemical operation. 


\subsection{Chemical bonding and XPS analysis}

The element-composition and surface state of the nanomaterials were examined by the XPS. Full XPS survey spectra (Figure 6a) showed the coetaneousness of $\mathrm{Si}, \mathrm{C}$, In, and O in $\mathrm{SiC}-\mathrm{In}_{2} \mathrm{O}_{3}$. The Si2p XPS spectra indicate that three electronic structures and chemical bonding states, $\mathrm{Si}-\mathrm{O}, \mathrm{Si}-\mathrm{O}_{2}$, and $\mathrm{Si}-\mathrm{C}$ are on the surface of the $\mathrm{SiC}$ fiber (Figure $6 \mathrm{~b}$ ). The binding energies of $\mathrm{Si}-\mathrm{O}_{2}$ and $\mathrm{Si}-\mathrm{O}$ obtained in the 101.28 and $100.14 \mathrm{eV}$ regions, respectively, had higher intensities than the Si-C XPS peak. The appearance of Si-O was higher than Si-C bonds, indicating that Si-O form of Si existed on the surface of the SiC fiber. Additionally, the O-element appearance can be derived from $\ln _{2} \mathrm{O}_{3}$ which is located on the surface of the $\mathrm{SiC}$-fiber [25]. The binding energy of $\mathrm{Si}-\mathrm{C}$ bonding is located at $99.05 \mathrm{eV}$ regions. Figure $6 \mathrm{c}$ shows the $\mathrm{C} 1 \mathrm{~s}$ XPS spectrum of the $\beta-S i C$ fiber as-well-as the possible deconvolution spectra of the C-element. $A$ total of four different bonding appearances were obtained in the $\mathrm{C} 1 \mathrm{~s}$ spectra: $\mathrm{C}-\mathrm{O}, \mathrm{C}-\mathrm{C}, \mathrm{C}=\mathrm{C}$, and $\mathrm{C}-\mathrm{Si}$ in the surface. The $\mathrm{C}-\mathrm{C}$ and $\mathrm{C}=\mathrm{C}$ bonding derived from the $\mathrm{SiC}$ and the peak intensities of $\mathrm{C}-\mathrm{C}$ and $\mathrm{C}=\mathrm{C}$ bonding were higher than that of $\mathrm{C}-\mathrm{O}$ bonding. The $\mathrm{C}$-Si bonding energy was obtained at $281.72 \mathrm{eV}$ region, indicating the metal appearance of the SiC-fiber furnace [25]. The peak intensity of $\mathrm{C}-\mathrm{O}$ was quite similar to that of $\mathrm{C}$-Si. Both oxygen and silica were derived from MO, showing successful interaction between $\mathrm{MO}$ and SiC-fibers. The XPS spectrum of In3d (in Figure $6 \mathrm{~d}$ ) was deconvoluted into two peaks: $\ln 3 \mathrm{~d}_{3 / 2}$ at $450.81 \mathrm{eV}$ and In3d $5 / 2$ at $443.34 \mathrm{eV}$ [26]. Figure 6e shows 01s XPS spectrum. The spectrum had four different chemical bonding states [26]. In the spectrum, Si-O, O-Me, C-O-C, and O-C bonding at 532.68, $530.79,528.59$ and $528.92 \mathrm{eV}$ binding energy regions were observed. Si-O and O-Me bonds are attributed to the contribution of MO. XPS results confirmed that each element had interconnection and that $\ln _{2} \mathrm{O}_{3}$ metal oxides successfully junctioned with $\mathrm{SiC}$ fibers and chemical bonds on the surface.

\subsection{Gas sensing performances}

The gas sensing performance of $\mathrm{xln}_{2} \mathrm{O}_{3}$ loaded with $\beta$-SiC-fibers was tested without gas and with $\left(\mathrm{O}_{2}\right.$ or $\mathrm{CO}_{2}$ ) gas purging. The $\mathrm{CV}$ profile was examined using a PGP201 potentiostat (A41A009). The test was recorded under a $(-500 \mathrm{~V})$ to $(1000 \mathrm{~V})$ potential range with a $(1 \mathrm{~A})$ to $(-1 \mathrm{~A})$ current. Cyclic voltammetry is one of the most commonly used electrochemical analysis techniques. The gas sensor material was used with three-different current collectors: Cu foil, FTO glass, and Ni foil. Figure $7(a, b, c)$ shows the results of the $\mathrm{CV}$ test of as-prepared electrodes without gas purging. Among them, the Ni-foil current collector drastically supported the electron transfer and electrochemical performance of the $\mathrm{SiC}-\mathrm{In}_{2} \mathrm{O}_{3}$ nanocomposite coated sensing material. In Figure $7 \mathrm{a}$, the high current density was $2.66 \times 10^{-2} \mathrm{~mA} / \mathrm{cm}^{2}$ on 1:0.5 M SiC- $\ln _{2} \mathrm{O}_{3}$ coated FTO sensor. The current density value was significantly reduced on 1:0.3 M SiC$\ln _{2} \mathrm{O}_{3}$ and 1:0.1 M SiC- $\ln _{2} \mathrm{O}_{3}$ nanocomposite was coated with sensor material. The current value of pure $\beta$-SiC fibers was approximately $3 \times 10^{-6} \mathrm{~mA} / \mathrm{cm}^{2}$, which might be due to the fact that pure $\beta-S i C$ fiber material had low reaction activity and low electrochemical performance at room temperature. The results of $\mathrm{CV}$ tests confirmed that the combination of $\mathrm{MO}$ and $\beta$-SiC-fibers drastically improved the electron transfer and electrochemical performance of the final nanocomposite material. In Figure 7b, the CV graph 
of the Ni-foil coated sensor shows a high current density value. The Ni foil current collector has more favourable compatibility with the $\mathrm{SiC}-\mathrm{In}_{2} \mathrm{O}_{3}$ nanocomposite. It drastically supported the electrochemical performance of the sensor material. A higher current value of $6 \times 10^{-2} \mathrm{~mA} / \mathrm{cm}^{2}$ was found for the 1:0.5 $\mathrm{M}$ $\mathrm{SiC}-\ln _{2} \mathrm{O}_{3}$ sensor material (in Figure $7 \mathrm{~b}$ ). The current value changeability between each electrode was not high, indicating that Ni-foil current collector had more stable properties on our synthesized $\mathrm{SiC}-\mathrm{In}_{2} \mathrm{O}_{3}$ binary nanocomposite. The current density value of sensor material coated $\mathrm{Cu}$ foil was quite higher than of coated FTO glass as shown in Figure 7c. However, the CV graph had a zig-zag profile. This indicated that the sensor material was not properly coated on the Cu-foil surface, leading to an irregular interconnection. These $\mathrm{CV}$ results indicated that sensor materials based on different electrical collectors coated with 1:0.5 M SiC- $\ln _{2} \mathrm{O}_{3}$ had good electroconductivity and good electrochemical ability, suggesting that these materials might have high gas sensitivity.

Figure 8 shows the results of the cyclic voltammetry test of the as-prepared gas sensor material under $\mathrm{CO}_{2}$ and $\mathrm{O}_{2}$ purging conditions at room temperature $\left(25^{\circ} \mathrm{C}\right)$. The gas sensor material was coated on $\mathrm{FTO}$ glass and $\mathrm{Ni}$ foil current collectors. Figures $8 \mathrm{a}$ and $8 \mathrm{~b}$ display the gas sensing performance of the coated FTO glass and the $\mathrm{Ni}$ foil current collector under $\mathrm{CO}_{2}$ gas purging conditions. Current density values of 1:0.5 M SiC- $-\ln _{2} \mathrm{O}_{3}$ were $8.34 \times 10^{-3} \mathrm{~mA} / \mathrm{cm}^{2}$ and $1.79 \times 10^{-2} \mathrm{~mA} / \mathrm{cm}^{2}$, respectively. The current change variation of the gas sensor was different due to conductivity. In the case of Ni foil, it had a porous structure to support the location/coating ability of the material, thus contributing to the electron transport potential. The sensing ability of the sensor material under $\mathrm{O}_{2}$-gas is displayed in Figures $8 \mathrm{c}$ and $8 \mathrm{~d}$.

Current density values of $1: 0.5 \mathrm{M} \mathrm{SiC}-\mathrm{In}_{2} \mathrm{O}_{3}$ were $9.82 \times 10^{-3} \mathrm{~mA} / \mathrm{cm}^{2}$ and $1.23 \times 10^{-2} \mathrm{~mA} / \mathrm{cm}^{2}$, respectively. Under $\mathrm{O}_{2}$ gas purging conditions, the variation of current density was higher than for $\mathrm{CO}_{2}$ gas detection. This indicated that the sensor material might have more excellent and effective sensing ability for $\mathrm{O}_{2}$ gas sensing at standard room temperature $\left(25^{\circ} \mathrm{C}\right)$ when the sensor material uses a Ni-foil current collector.

The gas sensing test was mainly realized by current change upon exposure to the target gas environment under a constant voltage [27]. Under room temperature conditions, activation of the electrode was less. Nevertheless, all sensor materials showed good sensing for $\mathrm{CO}_{2}$ and $\mathrm{O}_{2}$ gases. The current change variation on $1: 0.5 \mathrm{M} \mathrm{SiC}-\ln _{2} \mathrm{O}_{3}$ was higher than those of the other two gas sensor materials at standard room temperature. This provided evidence that this material had a more active sensing ability and that the reaction of gas on the electrode surface was more dynamic. The current change variation on 1:0.1 $\mathrm{M}$ $\mathrm{SiC}-\mathrm{In}_{2} \mathrm{O}_{3}$ was lower than other high amount of $\mathrm{MO}$ loaded $\beta$-SiC-binary nanocomposites, indicating that $0.1 \mathrm{M} \mathrm{In} \mathrm{O}_{3}$ irregularly spread on the surface of the $\mathrm{SiC}$ fiber and could not activate the sensing ability due to the lack of electron exchange.

The SiC-based gas sensor material had strong activation under high-temperature. In addition, the combination of $\beta-\mathrm{SiC}$ fibers with $\mathrm{MO}$ can bring excellent electronic conductivity and boost chemical activity (enhanced chemical activity and interactivity of the gas and electrode surface) [28]. Figure 9 
shows the results of the electrochemical test of the coated Ni-foil current collector under high temperatures without or with a gas purged state. Under high temperatures, differences among current density values of three different electrodes were not high, suggesting that these prepared electrodes could show quite similar sensing ability. However, the 1:0.5 M SiC- $-\ln _{2} \mathrm{O}_{3}$ nanocomposite coated electrode had a high current density value (Figure $9 \mathrm{a}$ ). Figures $9 \mathrm{~b}$ and $9 \mathrm{c}$ show electrochemical responses of $\mathrm{CO}_{2}$ and $\mathrm{O}_{2}$ gas with $x$-amount of $\operatorname{In}_{2} \mathrm{O}_{3}$ loaded $\beta-S i C$ fiber electrodes. The 1:0.5 M $\beta-S i C-\ln _{2} O_{3}$ electrode had high conductivity for $\mathrm{O}_{2}$ gas but low-conductivity for $\mathrm{CO}_{2}$ gas. Figure 10 (a and $\mathbf{b}$ ) displays the highest current density value of each gas sensor material without or with a gas purging condition at room temperature $\left(25^{\circ} \mathrm{C}\right)$ and high temperature $\left(350^{\circ} \mathrm{C}\right)$. The unit of current density value is $\mathrm{mA} / \mathrm{cm}^{2}$. The sensor material had quite strong sensitivity for $\mathrm{O}_{2}$ at room temperature as displayed in a bit graph. $\mathrm{O}_{2}$ gas had an electron acceptor behaviour. Oxygen gas strongly interacted with the surface of the sensor material. At a high temperature, a strong sensing ability of $\mathrm{SiC}-\mathrm{In}_{2} \mathrm{O}_{3}$ sensor was observed for $\mathrm{CO}_{2}$ gas. The possible gas sensing reactions on $\mathrm{SiC}-\ln _{2} \mathrm{O}_{3}$ nanomaterial at room and high temperatures are displayed in Figure 11. The gas sensing mechanism is based on the transfer of charges, in which the sensing material acts as an absorber or donor of charges. Charge transfer between the gas molecule and the sensing material will cause changes in sensing material properties. Gases such as $\mathrm{O}_{2}$ and $\mathrm{CO}_{2}$ tend to receive electrons from the sensor surface. The oxidizing gas (receiver) can increase the resistance of the sensor surface and reduce the resistance of the sensor by reducing the gas (donor). Gases such as $\mathrm{O}_{2}$ tend to receive electrons from the surface of the sensor, which is an oxygen-dominated gas that takes electrons from the surface of the metal oxide and converts them into ions that can be rapidly absorbed on the surface of a metal-oxide sensor (Figure 11a and $\mathbf{b}$ ). As a result, electrons on the surface become trapped, which increases the height of the potential barrier. On the other hand, it affects the surface conductivity of metal oxides or electron conduction. In the case of $\mathrm{CO}_{2}$, it has a linear bond and a stable structure with no lone pair of electrons (Figure 11c and d). The $\mathrm{CO}_{2}$ gas react with surface electrons of the gas sensors and made a form of $\left(\mathrm{CO}_{2}{ }^{-}\right)$. During a sensing test, surface electrons of the $\beta-\mathrm{SiC}-\mathrm{In}_{2} \mathrm{O}_{3}$ sensor are used to sense $\mathrm{CO}_{2}$, or $\mathrm{CO}_{2}$ gas receives electrons from the gas sensor so that the current density value $\left(\mathrm{mA} / \mathrm{cm}^{2}\right)$ of the gas sensor is significantly lower than that of a normal system or a no gas-purged system.

To conclude, the electron transfer ability between the target gases and sensor material strongly defines the sensing ability of $\mathrm{SiC}-\mathrm{In}_{2} \mathrm{O}_{3}$. Furthermore, the active parts of the surface affect the reaction between the gas and the surface on the sensor surface. $\mathrm{SiC}-\mathrm{In}_{2} \mathrm{O}_{3}$ nanocomposites contain varying amounts of $\mathrm{In}_{2} \mathrm{O}_{3}$ metal-oxide, which makes it possible to determine how they affect activities of gaseous materials. The high load of metal oxides strongly supports the electrochemical performance of $\beta$-SiC fibers, resulting in the formation of a high electron density Si-C-O-In bond sensor layer. The charge transfer process then becomes more active under the influence of the interface structure. In addition, functional $\beta-\mathrm{SiC}$ fibers had an abundant surface area on which $\mathrm{MO}$ can be homogeneously distributed. All factors mentioned above adequately explained the surface modification of the $\beta-S i C$ fiber, the change of electron-transfer activity, and the gas sensing ability. 


\section{Conclusion}

A SiC- $-\mathrm{I}_{2} \mathrm{O}_{3}$ nanocomposite containing new and unique properties was synthesized by the ultrasonication-method along with the hydrothermal method. The ultrasonication process was one of the leading techniques to achieve rapid nucleation of $\beta-\mathrm{SiC}-\mathrm{In}_{2} \mathrm{O}_{3}$ and improve solute transfer. The morphological state, molecule interaction, and crystal-structure of the nanocomposite were analyzed by XRD, SEM, TEM, EDX, Raman spectroscopy, XPS, and EIS. The gas sensing ability of the $\beta-\mathrm{SiC}^{-} \operatorname{In}_{2} \mathrm{O}_{3}$ nanocomposite was determined in terms of influencing factors such as the amounts of metal oxide, current collectors, and gas species $\left(\mathrm{CO}_{2}, \mathrm{O}_{2}\right.$, and without gas) at standard room temperature $\left(25^{\circ} \mathrm{C}\right)$ and high temperature $\left(350^{\circ} \mathrm{C}\right)$ conditions. The gas sensing ability of the $\mathrm{SiC}$ fiber was significantly enhanced by the loading of $\ln _{2} \mathrm{O}_{3}$ metal-oxide. In addition, the metal-oxide junction between SiC fibers was mainly due to the Si-C-O-In bond sensor layer with an effective electron-transfer ability. The electron transfer ability between the target gases and sensor material strongly defines the sensing ability of $\beta-S i C-\ln _{2} \mathrm{O}_{3}$. Furthermore, active parts of the surface can affect the reaction between the gas and the surface on the sensor surface. Our obtained data such as nanocomposite characteristics and gas sensing ability for $\mathrm{CO}_{2}$ and $\mathrm{O}_{2}$ gases adequately confirmed the successful junction of $\ln _{2} \mathrm{O}_{3}$ onto the $\mathrm{SiC}$ fiber. In conclusion, our proposed sample preparation method and selected gas sensing material junctions drastically upgraded the sensing performance of the $\beta-\mathrm{SiC}$ fiber and the sensor material.

\section{Declarations}

\section{Acknowledgment}

This research is supported by "The Project of Conversion by the Past R\&D Results" through the Ministry of Trade, Industry and Energy (MOTIE) (P0017347, 2021).

\section{References}

1. Li P, Cai Y, Fan $\mathrm{H}$, (2013) Porous thin sheet-based a- $-\mathrm{Fe}_{2} \mathrm{O}_{3}$-doped $\ln _{2} \mathrm{O}_{3}$ structures: hydrothermal synthesis and enhanced $\mathrm{Cl}_{2}$ sensing performance. RSC Adv, 3(44):22239-22245.

2. Thuy T.D. Nguyen, Ha-Nui Choi, M. Jamir Ahemad, Dung Van Dao, In-Hwan Lee, Yeon-Tae Yu, (2020) Hydrothermal synthesis of $\ln _{2} \mathrm{O}_{3}$ nanocubes for highly responsive and selective ethanol gas sensing, Journal of Alloys and Compounds 15, 820, 153133.

3. Kim SR, Hong HK, Kwon CH, Yun DH, Lee K, Sung YK (2000) Ozone sensing properties of $\operatorname{In}_{2} \mathrm{O}_{3}$-based semiconductor thick films. Sens Actuators B Chem 66(1-3):59-62.

4. Ivanovskaya $M$, Kotsikau D, Faglia G, Nelli $P$ (2003) Influence of chemical composition and structural factors of $\mathrm{Fe}_{2} \mathrm{O}_{3} / \mathrm{In}_{2} \mathrm{O}_{3}$ sensors on their selectivity and sensitivity to ethanol. Sens Actuators $B$ Chem 96(3):498-503. 
5. Yang W, Wan, P, Meng H, Hu J, Feng L, (2015) Supersaturation-controlled synthesis of diverse $\ln _{2} \mathrm{O}_{3}$ morphologies and their shape-dependent sensing performance, Cryst Eng Comm 17, 2989-2995.

6. Wang G, Park J, Wexler D, Park MS, Ahn JH (2007) Synthesis, characterization, and optical properties of $\ln _{2} \mathrm{O}_{3}$ semiconductor nanowires. Inorg Chem 46(12):4778-4780.

7. Lou X, Shi D, Liu S, Peng C (2007) Preparation of Cdln ${ }_{2} \mathrm{O}_{4}$ powder by sol-gel method and its $\mathrm{Cl}_{2}$ sensitivity properties. Sens Actuators B Chem 123(1):114-119.

8. Ong KG, Zeng K, Grimes CA (2002) A wireless, passive carbon nanotube-based gas sensor. IEEE Sens $J$ 2(2):82-88.

9. Bierwagen 0, (2015) Indium oxideda transparent, wide-band gap semiconductor for (opto)electronic applications, Semicond. Sci. Technol. 30, 024001.

10. Biswas MRUD, Oh WC (2018) Synthesis of $\mathrm{BiVO}_{4}$-GOPVDF nanocomposite: an excellent, newly designed material for high photocatalytic activity towards organic dye degradation by tuning band gap energies. Solid State Sci 80:22-30.

11. Zhang, D.; Zhao, Y.; Jiang, Y. (2014) SiC-SiC Bonding Methods for Ultra High-Temperature Pressure Sensors. Nanotechnol. Precis. Eng., 12, 258-262

12. Shankar P, Rayappan JBB (2015) Gas sensing mechanism of metal oxides: the role of ambient atmosphere, type of semiconductor and gases: a review. Sci Lett J 4(4):126.

13. Zhu $H$, Wang $X$, Yang F, Yang $X$ (2008) Template-free, surfactant less route to fabricate $\ln (\mathrm{OH})_{3}$ monocrystalline nanoarchitectures and their conversion to $\ln _{2} \mathrm{O}_{3}$. Cryst Growth Des 8(3):950-956.

14. Shanmugasundaram A, Ramireddy B, Basak P, Manorama SV, Srinath S (2014) Hierarchical $\ln (\mathrm{OH})_{3}$ as a precursor to mesoporous $\ln _{2} \mathrm{O}_{3}$ nanocubes: a facile synthesis route, mechanism of selfassembly, and enhanced sensing response toward hydrogen. J Phys Chem C 118(13):6909-6921.

15. Wang X, Li Y, Li Z, Zhang S, Deng X, Zhao G, Xu X (2019) Highly sensitive and low working temperature detection of trace triethylamine based on $\mathrm{TiO}_{2}$ nanoparticles decorated $\mathrm{CuO}$ nanosheets sensors. Sens Actuators B Chem 301:127019.

16. Wang Y, Lin B, Wang S, Cao X, (2014) Study on the system matching of ultrasonic vibration assisted grinding for hard and brittle materials processing. Int. J. Mach. Tools Manuf 77, 66-73.

17. Sun L, Han C, Wu N, Wang B, Wang Y. (2018) High Temperature Gas Sensing Performances of Silicon Carbide Nanosheets with an n-p Conductivity Transition. RSC Adv, 8, 13697-

18. Sun L, Wang B, Wang Y. (2018) A Novel Silicon Carbide Nanosheet for High-Performance Humidity Sensor. Adv. Mater. Interfaces, 5, 1701300.

19. Soo M.T, Cheong K.Y, Noor A.F.M. (2010) Advances of SiC Based MOS Capacitor Hydrogen Sensors for Harsh environment Applications. Sens. Actuators, B, 151, 39-

20. Li X, Gao F, Wang L, Jiang L, Chen S, Yang W. (2019) Enhanced Piezoresistive Performance of 3C-SiC Nanowires by Coupling with Ultraviolet Illumination. J. Mater. Chem. C, 7, 13384- 
21. Yu H, Wang Q, Yang L, Dai B, Zhu J, Han J. (2019) Ultraviolet-Visible Light Photoluminescence Induced by Stacking Faults in 3C-SiC Nanowires. Nanotechnology, 30, 235601.

22. Friedland E, Malherbe J.B, van der Berg N.G, Hlatshwayo T, Botha A.J, Wendler E, Welch W, (2009) Study of silver diffusion in silicon carbide, J. Nucl. Mater. 389, 326-331.

23. Burton J.C, Long F.H, Ferguson I.T, (1999) Resonance enhancement of electronic Raman scattering from nitrogen defect levels in silicon carbide Raman scattering from anisotropic LO-phononplasmon-coupled mode in n-type $4 \mathrm{H}$-and 6H, Cit. J. Appl. Phys. 86, 6268.

24. Lee H, Kim B, Gao C.Y, Choi H.J, Ko J.H, Seo C.H, Park J, (2019) Raman spectroscopy study of solution processed $\ln _{2} \mathrm{O}_{3}$ thin films: effect of annealing temperature on the characteristics of $\operatorname{In}_{2} \mathrm{O}_{3}$ semiconductors and thin-film transistors, Molecular Crystals and Liquid Crystals, 679:1, 38-47.

25. Lian S, Bing W, Yingde W, (2020) High-Temperature Gas Sensor Based on Novel Pt Single Atoms@SnO 2 Nanorods@SiC Nanosheets Multi-heterojunctions, ACS Appl. Mater. Interfaces, 12, 21808-21817.

26. Bayon R, Mafftiotte C, Herrero J, (1999) Chemical bath deposition of indium hydroxy sulphide thin films: process and XPS characterization, Thin Solid Films 353, 100-107.

27. Kolmakov A, Zhang Y, Cheng G, Moskovits $\mathrm{M}$, (2003) Detection of $\mathrm{CO}$ and $\mathrm{O}_{2}$ using tin oxide nanowire sensors, Adv. Mater. 15, 997-1000.

28. Gai $L, M a L$, Jiang $H$, Ma $Y$, Tian $Y$, $L i u H$, (2012) Nitrogen-doped $\ln _{2} O_{3}$ nanocrystals constituting hierarchical structures with enhanced gas-sensing properties, Cryst. Eng. Comm. 14, 7479-7486

\section{Figures}



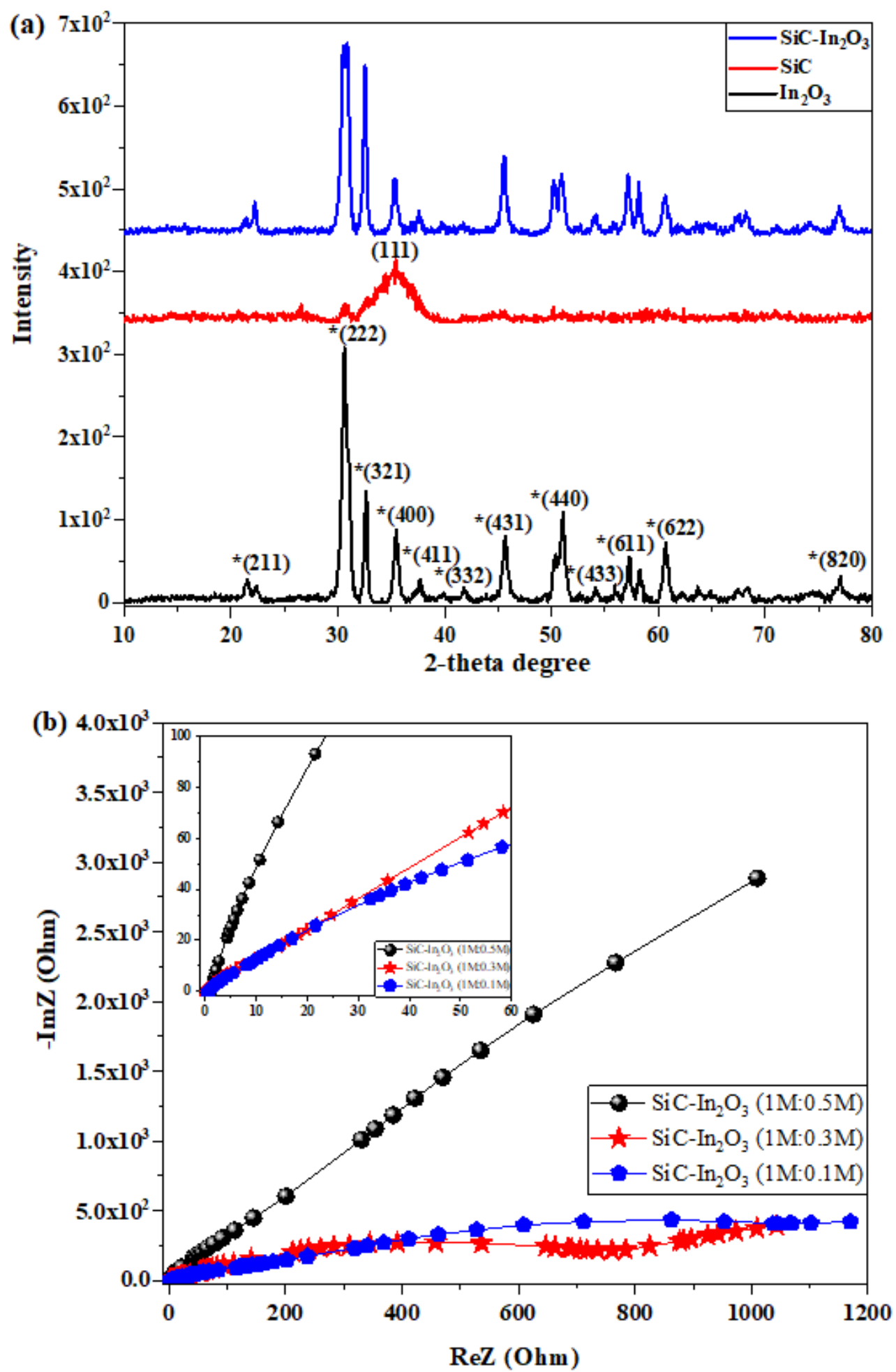

Figure 1

. (a) XRD pattern; and (b) EIS test of the In203, SiC fiber and SiC-In2O3 nanocomposite. 


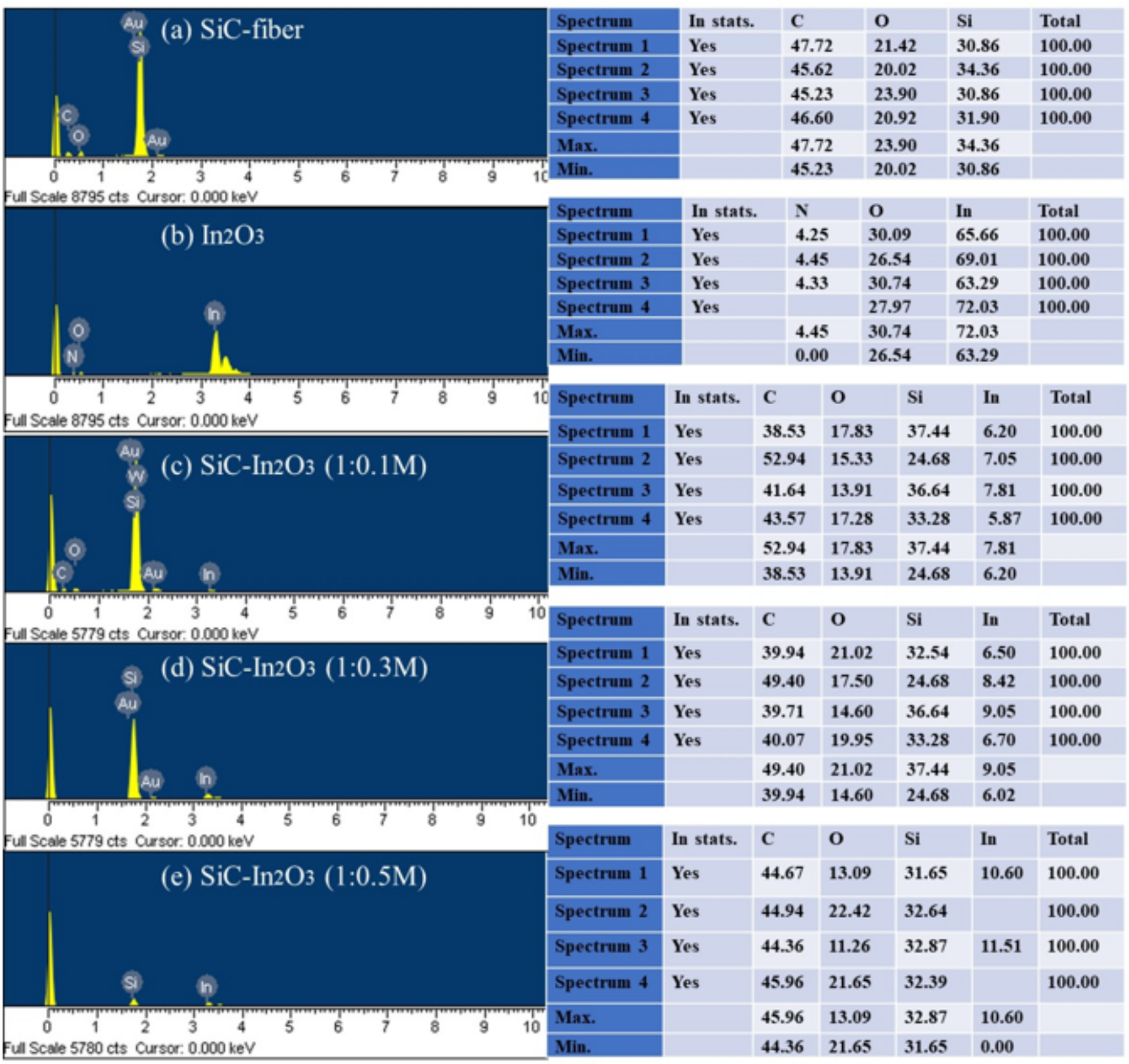

\section{Figure 2}

EDX analysis of the In203, SiC fiber and SiC-In203 nanocomposite. 


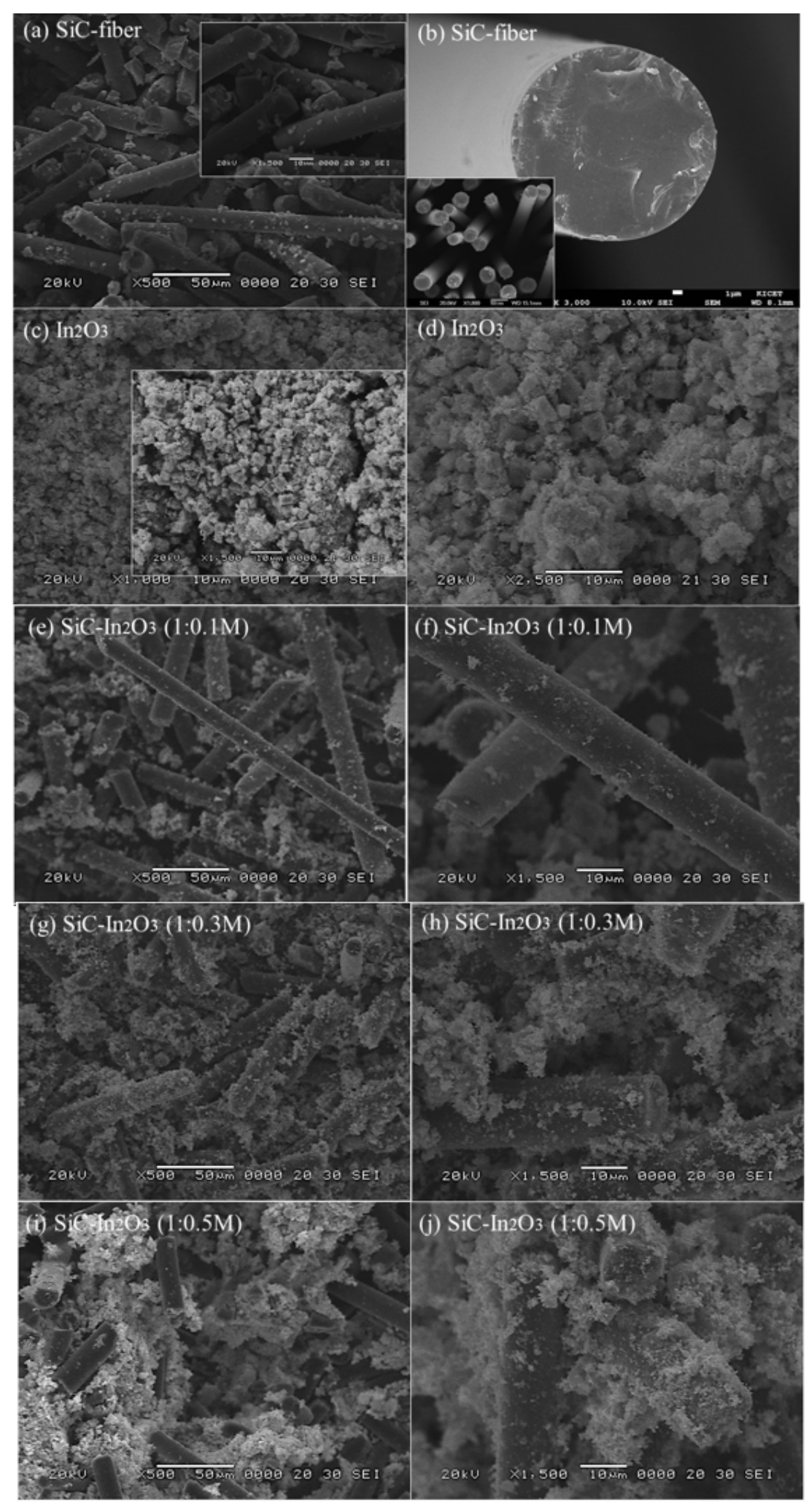

\section{Figure 3}

SEM analysis of the (a, b) SiC fiber, (c, d) In2O3 and (e-j) SiC-In2O3 nanocomposite. 


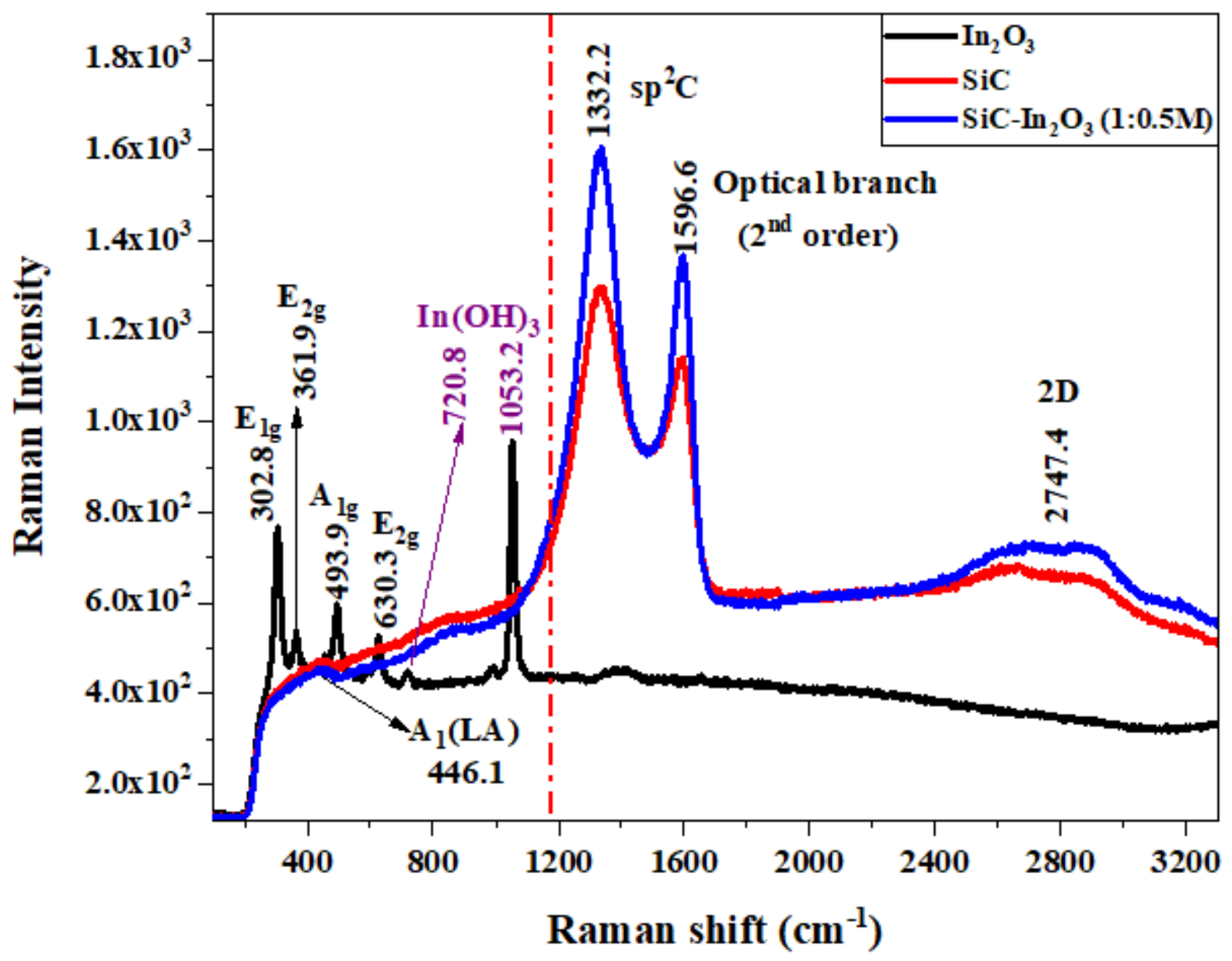

Figure 4

Raman spectra of In203, pure SiC fiber and SiC-In2O3 nanocomposite (thermal annealing at $400{ }^{\circ} \mathrm{C}$ ). 

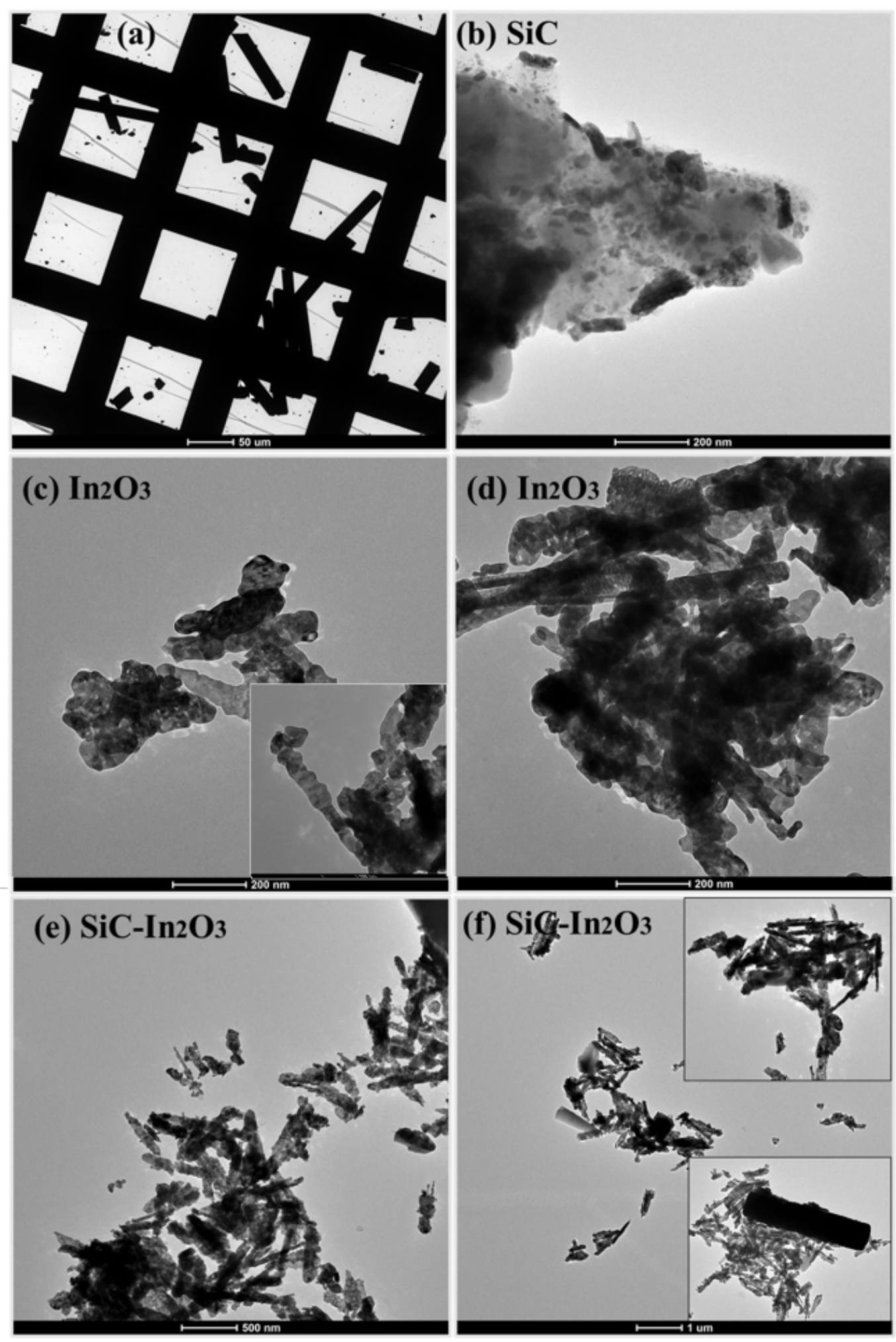

Figure 5

TEM images of the $(a, b)$ pure $\mathrm{SiC},(c, d) \operatorname{In} 2 \mathrm{O} 3$ and $(e, f) \operatorname{SiC}-\ln 2 \mathrm{O} 3(1: 0.5 \mathrm{M})$ nanocomposite (thermal annealing at $400^{\circ} \mathrm{C}$ ) 

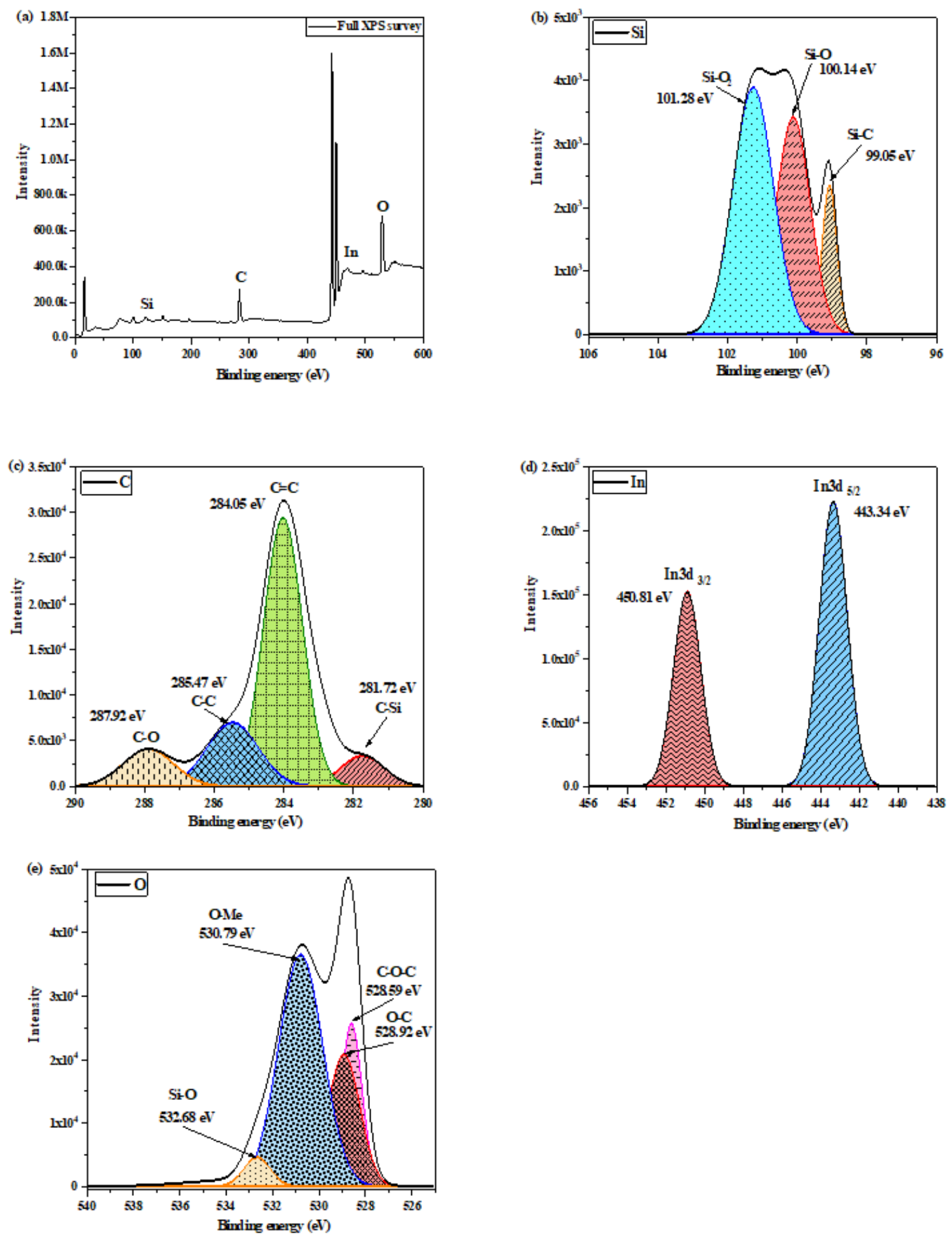

Figure 6

XPS analysis of the SiC-In2O3 nanocomposite (a), Si (b), C (c), In (d) and O (e). 

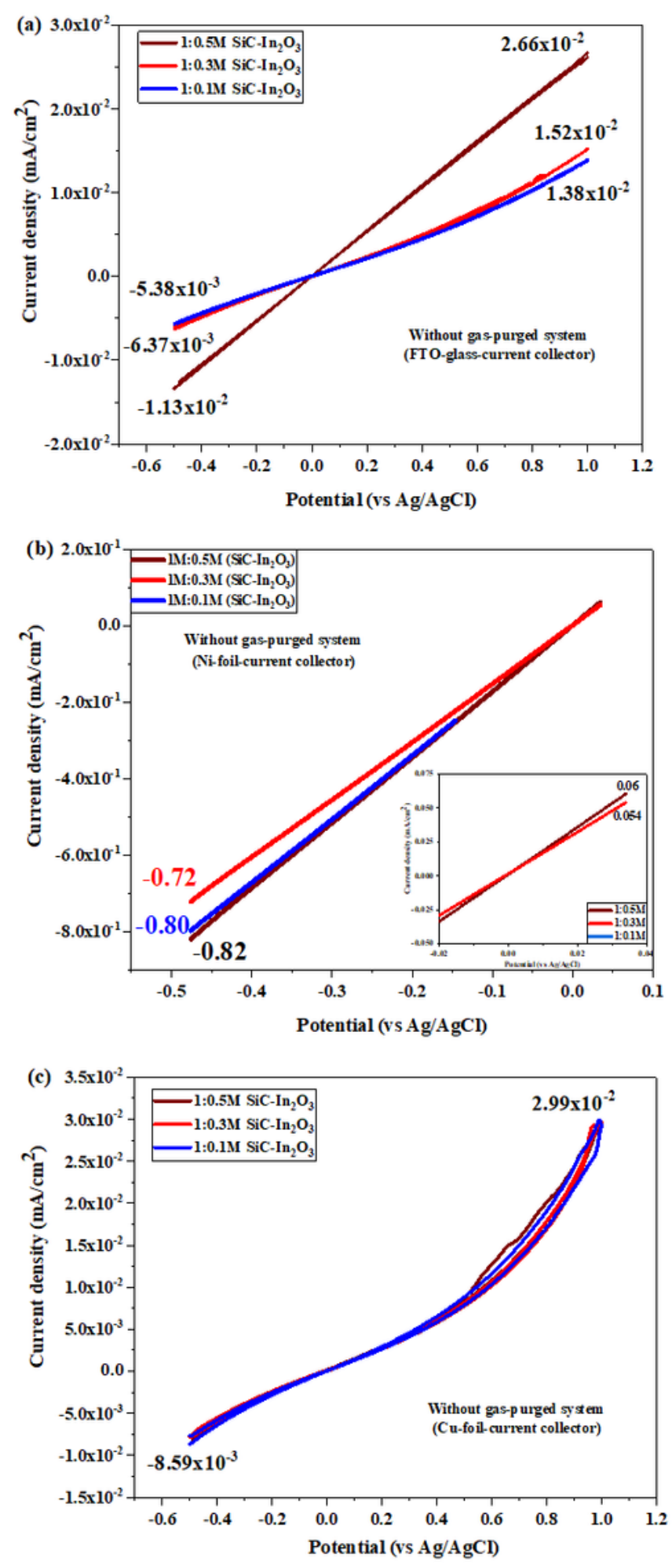

\section{Figure 7}

CV test of the as-prepared electrode without gas-purging conditions on (a) FTO glass, (b) Ni foil, and (c) Cu foil current collector. 

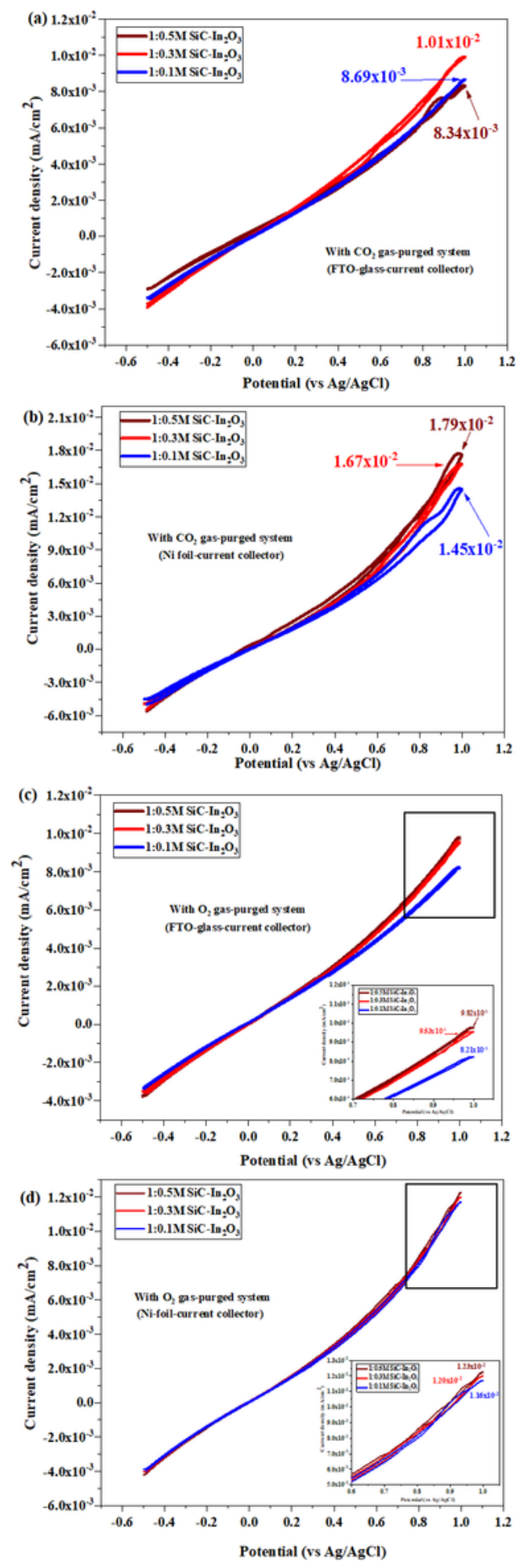

Figure 8

$\mathrm{CV}$ test of the as-prepared electrode under $\mathrm{CO} 2$ and 02 gas-purging conditions at normal room temperature. 

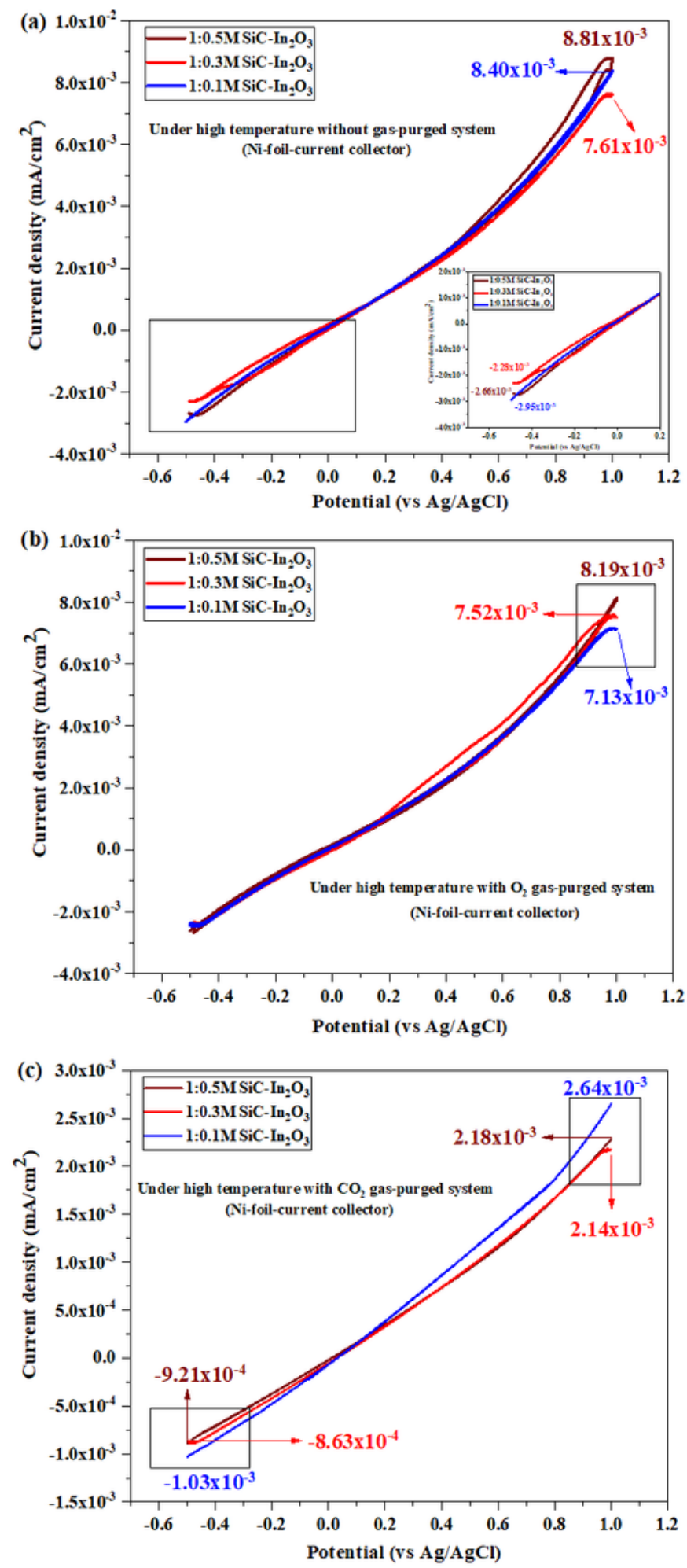

\section{Figure 9}

$\mathrm{CV}$ test of the as-prepared electrode under $350^{\circ} \mathrm{C}$ temperature heat treatment with (a) without gas purging, (b) 02 gas-purging and (c) $\mathrm{CO} 2$ gas purging system. 


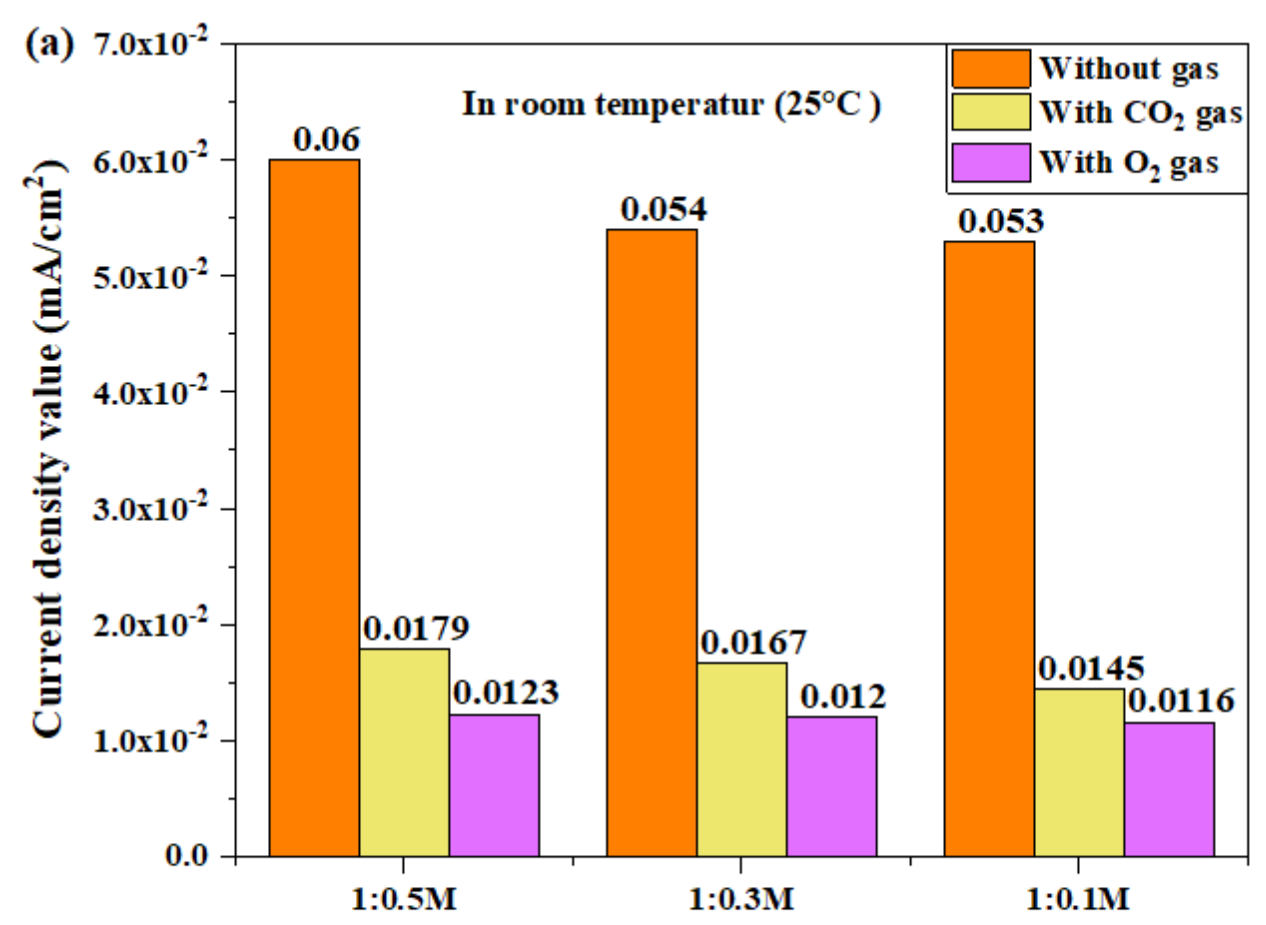

Gas sensing nanomaterial

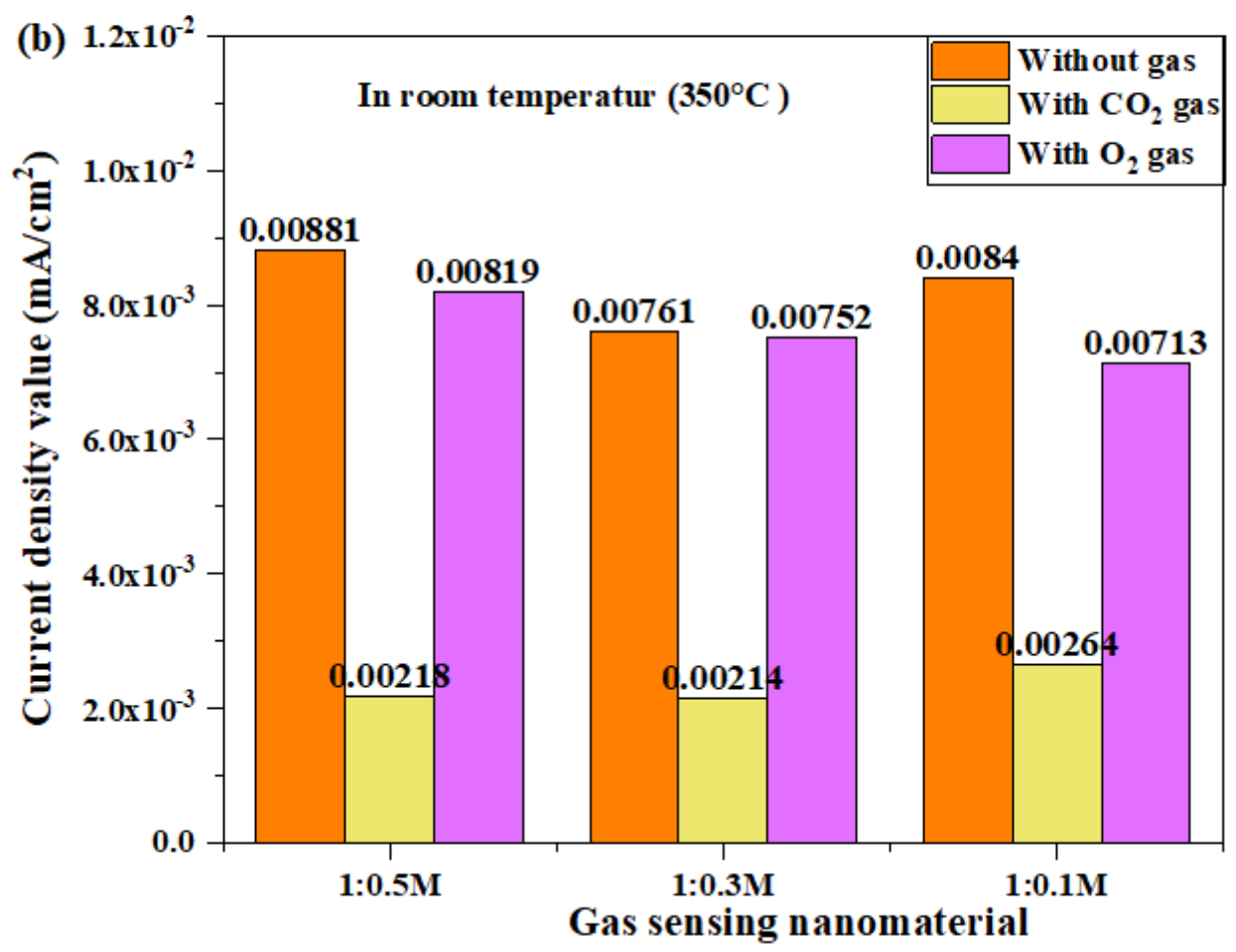

Figure 10

Current density value of the gas sensor under gas and without gas at room temperature and high temperature conditions. 
(a) In room temperature $=$ Sensitivity is strong

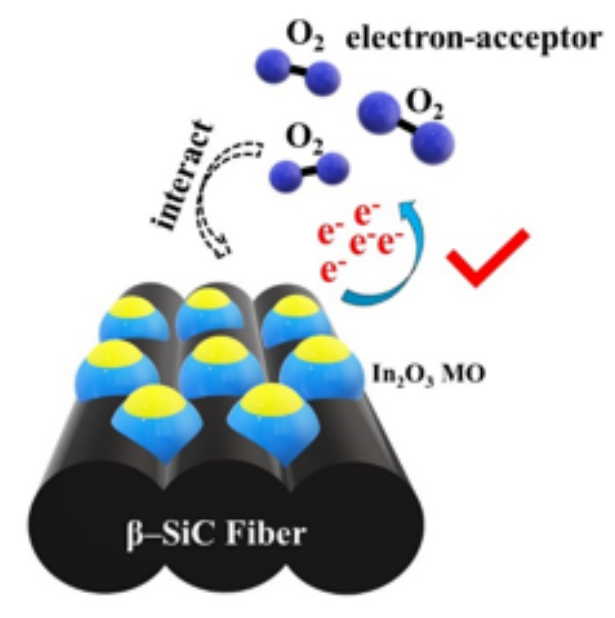

(c) In room temperature $=$ Sensitivity is strong

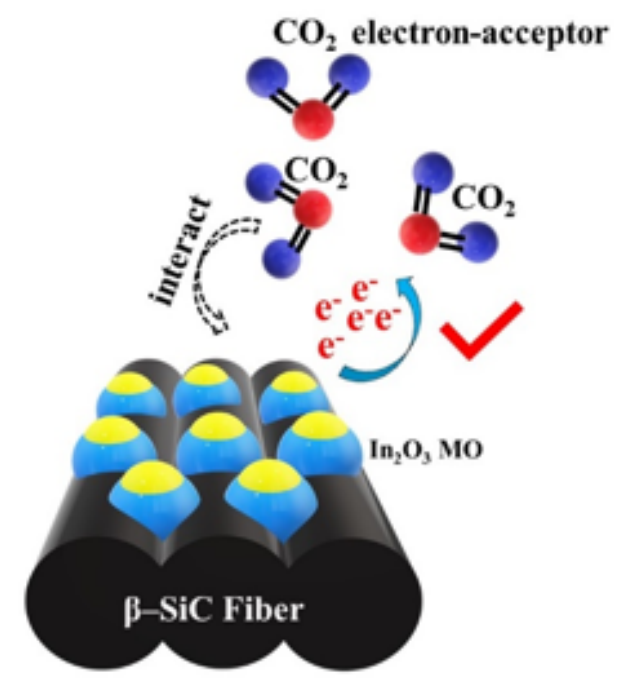

(b) In high temperature $=$ Sensitivity is weak

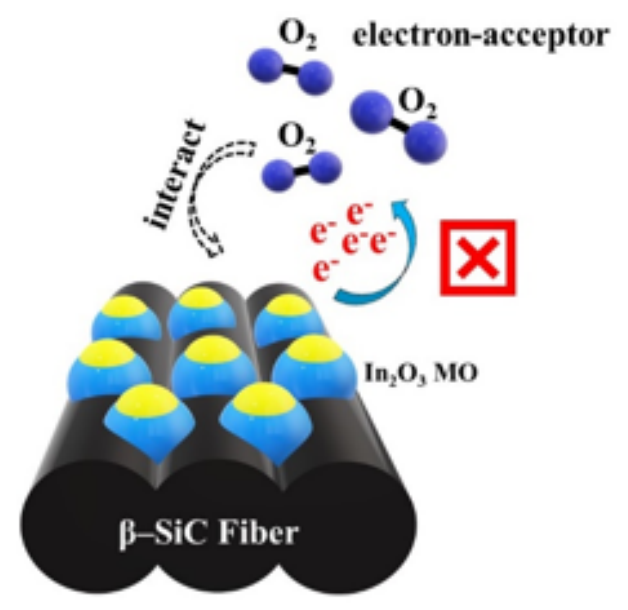

(d) In high temperature $=$ Sensitivity is strong

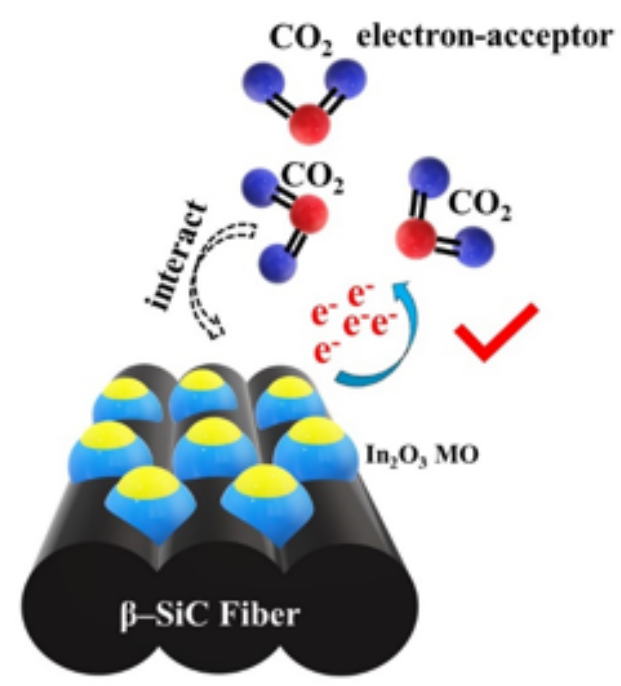

\section{Figure 11}

Schematic illustration of the $\mathrm{CO} 2$ and 02 gas sensing performance on the SiC-In2O3 sensor at room temperature and high temperature. 